An effective strategy to enhance the dielectric constant of organic semiconductors - CPDTTPD-based low bandgap polymers bearing oligo(ethylene glycol) side chains

Peer-reviewed author version

BREBELS, Jeroen; Douvogianni, Evgenia; DEVISSCHER, Dries; THIRUVALLUR EACHAMBADI, Ragha; MANCA, Jean; LUTSEN, Laurence; VANDERZANDE, Dirk; Hummelen, Jan C. \& MAES, Wouter (2018) An effective strategy to enhance the dielectric constant of organic semiconductors - CPDTTPD-based low bandgap polymers bearing oligo(ethylene glycol) side chains. In: JOURNAL OF MATERIALS CHEMISTRY C, 6(3), p. 500-511.

DOI: $10.1039 / \mathrm{c} 7 \mathrm{tc05264b}$

Handle: http://hdl.handle.net/1942/26178 


\section{An Effective Strategy to Enhance the Dielectric Constant of Organic Semiconductors - CPDTTPD-Based Low Bandgap Polymers Bearing Oligo(Ethylene Glycol) Side Chains}

Jeroen Brebels, ${ }^{a}$ Evgenia Douvogianni, ${ }^{b}$ Dries Devisscher, ${ }^{a}$ Raghavendran Thiruvallur Eachambadi, ${ }^{c}$ Jean Manca, ${ }^{c}$ Laurence Lutsen, ${ }^{d}$ Dirk Vanderzande, ${ }^{a, d}$ Jan C. Hummelen, ${ }^{* b}$ and Wouter Maes*a,d
(a) UHasselt - Hasselt University, Institute for Materials Research (IMO-IMOMEC), Design \& Synthesis of Organic Semiconductors (DSOS), Agoralaan, 3590 Diepenbeek, Belgium
(b) Stratingh Institute for Chemistry, Zernike Institute for Advanced Materials, University of Groningen, Nijenborgh 4, 9747 AG, Groningen, The Netherlands
(c) UHasselt - Hasselt University, X-LAB, Agoralaan, 3590 Diepenbeek, Belgium
(d) IMEC, Associated lab IMOMEC, Wetenschapspark 1, 3590 Diepenbeek, Belgium
Corresponding authors: E-mail: j.c.hummelen@rug.nl; wouter.maes@uhasselt.be 


\begin{abstract}
Conjugated polymers applied in organic electronics (notably photovoltaics and photodetectors) generally exhibit relatively low dielectric constants $\left(\varepsilon_{r} 3-4\right)$, which leads to significant recombination losses of photogenerated excitons. As a direct consequence, the performance of the resulting devices is inherently restricted. Some efforts have been directed toward increasing $\varepsilon_{\mathrm{r}}$ of the photoactive organic compounds, but the general knowledge on the impact of specific structural variations on the dielectric constant and the final device output remains rather limited. In this study, this problem is addressed. A series of push-pull type alternating copolymers is synthesized based on $4 H$-cyclopenta[2,1-b:3,4- $\left.b^{\prime}\right]$ dithiophene (CPDT) and 4H-thieno[3,4-c]pyrrole-4,6(5H)-dione (TPD) subunits, with the aim to increase the dielectric constant using oligo(ethylene glycol) side chains. The amount of glycol substituents on the polymer backbone is gradually raised to systematically investigate its influence on the dielectric properties. Impedance measurements reveal a doubling of the dielectric constant (up to $\varepsilon_{r} 6.3$ ) with respect to the reference polymer. Upon applying these materials in bulk heterojunction polymer solar cells, an efficiency of $4.4 \%$ is obtained for the best-performing device, with a particularly higher short-circuit current and improved fill factor compared to the pristine alkyl-substituted polymer. Importantly, a non-halogenated solvent - beneficial toward 'green' processing - can also be applied for the active layer deposition, affording comparable results.
\end{abstract}




\section{Introduction}

Organic semiconductors are versatile active materials for high-performance (opto)electronic devices such as light-emitting diodes (OLEDs), ${ }^{1}$ field-effect transistors (OFETs), ${ }^{2}$ photodetectors (OPDs), ${ }^{3}$ photovoltaics (organic and hybrid perovskite PVs) ${ }^{4}$ and thermoelectrics. ${ }^{5}$ Because of their high potential toward fully flexible, solution processed and low-cost organic solar cells, a lot of research has been done in this direction. ${ }^{6-13}$ Many studies have focused on the variation of the building blocks of so-called 'push-pull', low bandgap, electron donor-type polymers, targeting optimal absorption features and energy level alignment, while the solubilizing side chains are tuned to optimize the miscibility with the electron acceptor component in the bulk heterojunction (BHJ) photoactive layer. ${ }^{14}$ Thorough understanding of structure-property relations has been achieved and recent advances have pushed the power conversion efficiencies (PCEs) over $13 \% .{ }^{15}$ Intimate mixing of the electron donor and acceptor materials is essential to achieve these high efficiencies because of the limited diffusion length of the excitons formed upon the absorption of light. ${ }^{16}$ This is a direct consequence of the strong Coulombic interactions of holes and electrons, caused by the rather low dielectric constants (i.e. static relative permittivity; $\varepsilon_{r} \sim 3-4$ ) and high exciton binding energies in organic semiconductors. ${ }^{17}$ The modest $\varepsilon_{r}$ of current generation organic semiconductors hence puts a limit on the PCE in comparison with inorganic or hybrid organicinorganic solar cells.

Somewhat surprisingly, research on alternative high- $\varepsilon_{r}$ conjugated small molecules and polymers has remained rather limited, although a number of specific features of high interest for OPV and other organic electronic applications can be achieved upon increasing the dielectric constant. ${ }^{18-20}$ Simulations have shown that PCEs of more than $20 \%$ can be realized by taking into account an increased (active layer) $\varepsilon_{\mathrm{r}}$ up to $10 .{ }^{21}$ Higher dielectric constants can diminish important loss processes originating from Coulombic interactions between oppositely charged carriers. ${ }^{21}$ The beneficial effect of an increasing $\varepsilon_{r}$ can easily be understood as the resulting lower binding energy of the charge transfer excitons (precursors to the free electrons and holes) will allow faster charge separation (with reduced energy losses) and thereby afford a higher photovoltaic efficiency. ${ }^{22}$ Furthermore, reduction of the bimolecular recombination process allows the production of OPV devices with thicker films for better light harvesting and further improved performance. ${ }^{23,24}$ In this case, even single junction organic solar cells could be foreseen. ${ }^{21}$ When applying these high- $\varepsilon_{\mathrm{r}}$ organic semiconductors as charge selective electrode materials in hybrid perovskite PVs, the dielectric contrast between the perovskite active layer and the charge selective transport layer can be lowered. ${ }^{25}$ In applications where the organic semiconductor is doped, an increased $\varepsilon_{\mathrm{r}}$ is also very beneficial. Thus, a wide range of applications can be targeted with high- $\varepsilon_{r}$ organic semiconducting materials.

Most studies aiming to increase $\varepsilon_{r}$ have focused on polarizable oligo(ethylene glycol) (OEG) side chains. ${ }^{18-20,24,26-28}$ These glycol substituents are easily introduced and do not only increase the polarity of the organic semiconducting materials, but also provide a higher chain flexibility, facilitating closer $\pi-\pi$ stacking and thereby promoting charge carrier mobility. ${ }^{29}$ Because of this improved chain flexibility, reorientation of the dipoles occurs much faster, which 
potentially increases $\varepsilon_{\mathrm{r} .}{ }^{26-28}$ Moreover, OEG moieties are also known to increase the material solubility in more hydrophilic solvents, enabling to reduce the ecological footprint of the device preparation by allowing processing from environmentally more acceptable solvents (e.g. alcohols). ${ }^{30}$ Greener processing is for instance highly desired to enhance the credibility and facilitate commercialization of organic photovoltaics as a truly renewable energy source. ${ }^{31}$

The first attempt to increase the dielectric constant of an organic semiconductor using OEG was done by Vanderzande et al. using a PPV (poly( $p$-phenylene vinylene)) polymer. ${ }^{18} \mathrm{~A}$ maximum $\varepsilon_{r}$ of 5.5 (vs. 3 for MDMO-PPV) was achieved by the introduction of 2 tri(ethylene glycol) (TEG) side chains on the polymer backbone (diPEO-PPV). Initial solar cell results were reported as well, but they remained very low. Later results from the same group showed a non-optimal BHJ morphology for a similar PPV with one single TEG side chain (PEO-PPV) because of compatibility issues with the applied fullerene acceptor, an issue more often encountered when adding glycol substituents. ${ }^{32}$ As a result, again a low PCE $(0.5 \%)$ was achieved. Nevertheless, an enhanced charge dissociation was obtained compared to standard PPV derivatives. More recent results by Wang et al. illustrate the strong potential of OEGdecorated materials for $\varepsilon_{r}$ (and OPV) enhancement. ${ }^{24}$ Diketopyrrolopyrrole (DPP) based polymers bearing different OEG side chains were reported to show reasonably high $\varepsilon_{\mathrm{r}}$ values (up to 5.5) and a polymer solar cell efficiency up to 5.4\% was achieved, similar to the reference polymer with regular alkyl side chains. On the other hand, Jahani et al. reported an $\varepsilon_{r}$ increase up to 5.7 for a fullerene derivative with a TEG substituent (vs. 3.9 for regular [60]PCBM), without severely affecting the optical and electrochemical material properties. ${ }^{19}$

Despite the exciting prospects, the promises of a 'novel OPV efficiency regime' ${ }^{21}$ by increasing the dielectric constant have not been realized so far. ${ }^{33} \mathrm{It}$ is clear that more dedicated studies are required to establish proper structure - dielectric constant - device efficiency relations. Lots of questions remain with respect to the effect of both the backbone and side chain structures. The impact of the enhanced $\varepsilon_{r}$ on the final solar cell efficiency is also hard to evaluate, as it cannot be isolated from other effects (e.g. on blend morphology, crystallinity and charge transport) imposed by the structural variations. Moreover, the dielectric constant measurements should be performed with great care to obtain reliable $\varepsilon_{r}$ values, allowing proper comparison. In the present study, four novel low bandgap copolymers are synthesized based on $4 H$-cyclopenta[2,1- $\left.b: 3,4-b^{\prime}\right]$ dithiophene (CPDT) as the donor and 1,3-dibromo- $4 H$ thieno[3,4-c]pyrrole-4,6(5H)-dione (TPD) as the acceptor building block. ${ }^{34,35}$ These subunits were specifically selected for the ease of gradual introduction of multiple OEG side chains on these materials, allowing a systematic study. The dielectric constants are evaluated by means of impedance spectroscopy, resulting in a maximum $\varepsilon_{r}$ value of 6.3 , among the highest values reported so far for organic semiconductors, and with very low error bars. ${ }^{18-20,24,26-28,33,36-39}$

\section{Results and discussion}

\section{Material synthesis and characterization}

To allow systematic evaluation of the effect of the number of OEG substituents, these were introduced on either of the two building blocks required for the push-pull polymer synthesis via Stille polycondensation. For the synthesis of the stannylated CPDT monomer with one 
single TEG side chain, different literature procedures were combined to come up with a shorter and easier reaction sequence to synthesize CPDT precursor 4 (Scheme 1), allowing asymmetric side chain substitution. ${ }^{40-43}$ The first step involved the coupling of 3 bromothiophene via the Gronowitz dithienyl synthesis, employing lithiation of the 2-position with lithium diisopropylamide (LDA) followed by coupling through the use of $\mathrm{CuCl}_{2}$. In the next step, cyclization was performed using dimethylcarbamoyl chloride to obtain $4 \mathrm{H}$ cyclopenta[2,1-b:3,4- $\left.b^{\prime}\right]$ dithiophen-4-one (3). A Wittig-type carbonyl olefination reaction with 2-ethylhexylphosphonium bromide was then applied to obtain product 4 . The exocyclic double bond was reduced with $\mathrm{LiAlH}_{4}$ and an in-situ reaction was performed with 1-chloro-2(2-(2-methoxyethoxy)ethoxy)ethane. In the last step, distannylation afforded CPDT monomer 6. The standard conditions for stannylation were slightly adapted to obtain a better yield. A larger excess of $n$-BuLi was needed to force the reaction toward the distannylated product, probably due to the hygroscopic character of the TEG side chain.

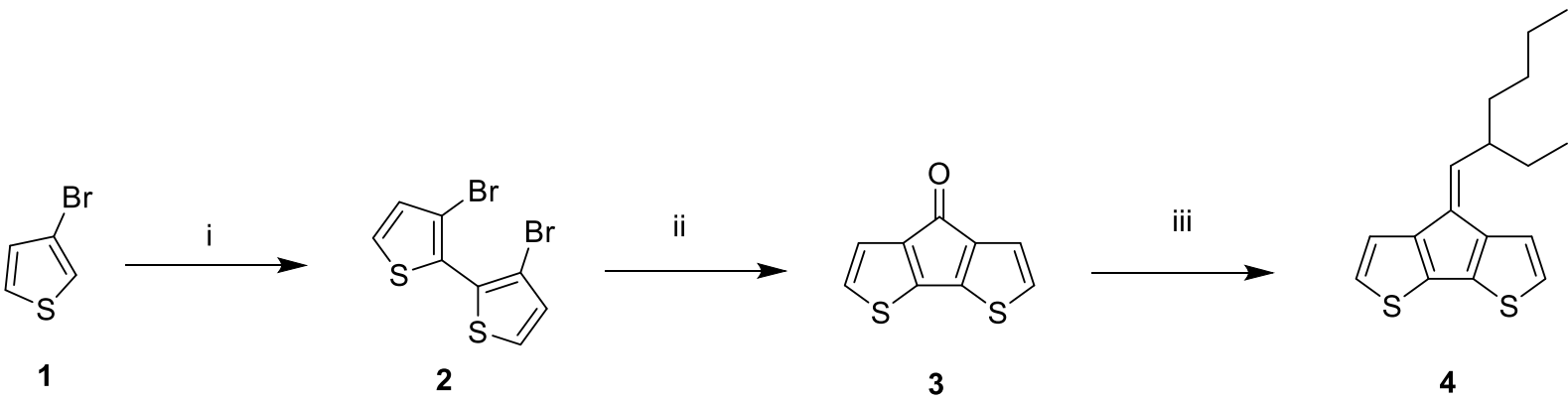

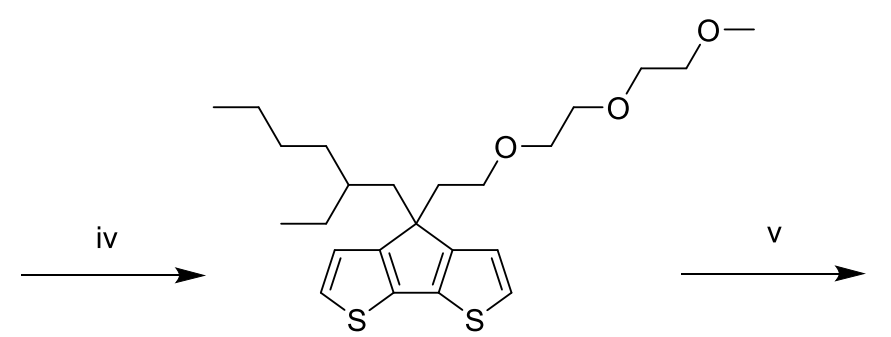

5

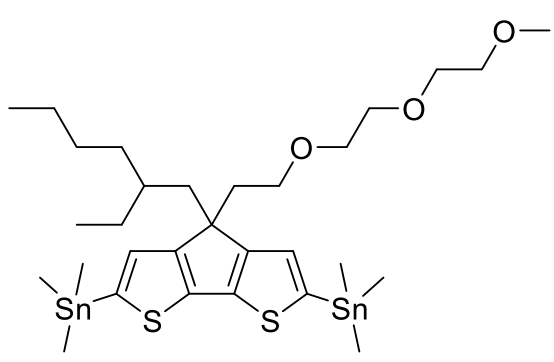

6

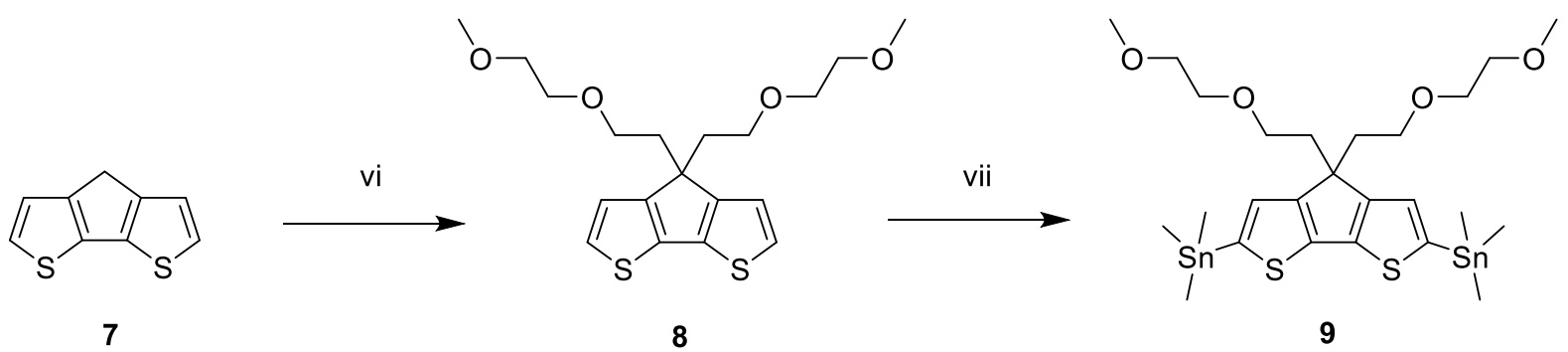

Scheme 1. Synthesis of bis(stannyl)-CPDT monomers 6 and 9: i) LDA, $\mathrm{CuCl}_{2}$, THF, overnight at RT; 72\%; ii) $n$-BuLi, ClCONMe 2 , THF, overnight at RT; 76\%; iii) 2-ethylhexylphosphonium bromide, $n$-BuLi, THF, 2 h at $-78^{\circ} \mathrm{C}$, overnight at RT; 77\%; iv) $\mathrm{LiAlH}_{4}$, 1-chloro-2-(2-(2-methoxyethoxy)ethoxy)ethane, MTBE, 60 ${ }^{\circ} \mathrm{C}$, overnight at RT; $62 \%$; v) $n$-BuLi, $\mathrm{SnMe}_{3} \mathrm{Cl}, 1.5 \mathrm{~h}$ at $-78{ }^{\circ} \mathrm{C}$, overnight at RT; $54 \%$; vi) 1-chloro-2-(2- 
methoxyethoxy)ethane, $\mathrm{KI}, \mathrm{KOH}, \mathrm{DMSO}$, overnight at RT; $58 \%$; vii) $n$-BuLi, $\mathrm{SnMe}_{3} \mathrm{Cl}, 1.5 \mathrm{~h}$ at $-78{ }^{\circ} \mathrm{C}$, overnight at RT; $65 \%$.

A shorter sequence was used to synthesize symmetrical di(ethylene glycol) (DEG) substituted CPDT monomer $\mathbf{9}$ (Scheme 1). The two side chains were introduced on commercially available CPDT with the aid of $\mathrm{KOH}$ and $\mathrm{Kl}$, followed by a distannylation reaction to obtain the desired monomer. Also in this case it was important to use at least 6 equivalents of $n$-BuLi to force the reaction toward the distannylated product. The final CPDT monomers ( $\mathbf{6}$ and $\mathbf{9}$ ) were purified by (recycling) preparative size exclusion chromatography (prep-SEC) to eliminate residual impurities, allowing a proper stoichiometric balance in the polymerization reactions.

To synthesize the TPD acceptor building block, a literature procedure was used (Scheme 2), ${ }^{44}$ starting from thiophene-3,4-dicarboxylic acid (10) which was first brominated. Acetic anhydride was then added in the next step, which resulted in a ring closure to obtain compound 12. Ammonia was subsequently added, which again opened up the ring, resulting in compound 13 containing a carbamoyl and a carboxylic acid group. In the next reaction, another ring closure was performed to obtain the bare TPD unit 14 without any side chain attached. Through reaction with 1-bromo-2-(2-methoxyethoxy)ethane in the presence of $\mathrm{KOH}$, the DEG substituted TPD monomer 15 was finally obtained. Recrystallization from methanol afforded the molecule in high purity, ready for the polymerization reaction.

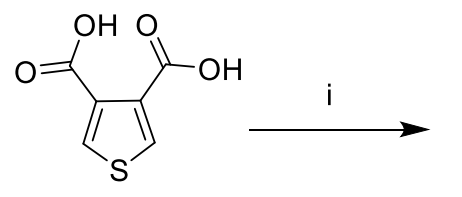

10

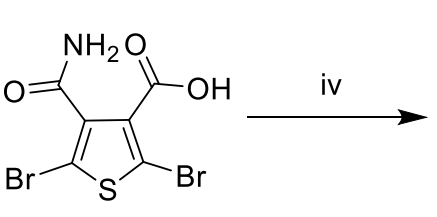

13

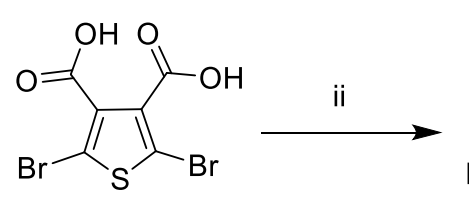

11

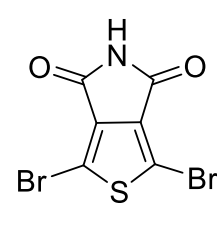

14

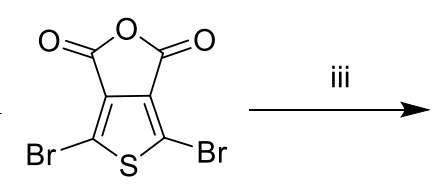

12

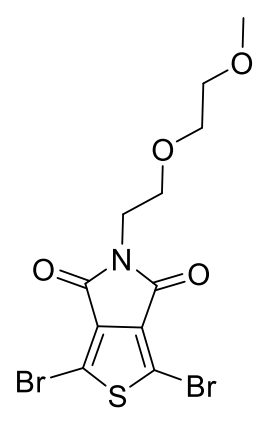

15

Scheme 2. Synthesis of dibromo-TPD monomer 15 : i) $\mathrm{Br}_{2}$, acetic acid, overnight at $85^{\circ} \mathrm{C} ; 67 \%$; ii) acetic anhydride, overnight at $140{ }^{\circ} \mathrm{C}$; $96 \%$; iii) $\mathrm{NH}_{3}(7 \mathrm{M}$ in $\mathrm{MeOH}), \mathrm{THF}, 30 \mathrm{~min}$, then $\mathrm{HCl}(12 \mathrm{M}), 30 \mathrm{~min}$; 73\%; iv) $\mathrm{Et}_{3} \mathrm{~N}, 1,1^{\prime}$-carbonyldiimidazole, THF, $12 \mathrm{~h}$ at RT; 81\%; v) NaH (60\%), DMF, $1 \mathrm{~h}$ at RT, then 1bromo-2-(2-methoxyethoxy)ethane, $12 \mathrm{~h}$ at $50{ }^{\circ} \mathrm{C} ; 56 \%$.

The different monomers $(6,9,15$ and regular 1,3-dibromo-5-octyl-4H-thieno[3,4-c]pyrrole4,6(5H)-dione) were then copolymerized using the Stille polycondensation approach under standard conditions ( 2 mol\% $\mathrm{Pd}_{2} \mathrm{dba}_{3}, 8 \mathrm{~mol} \% \mathrm{P}(\mathrm{o} \text {-tol })_{3}$, toluene/DMF 5/1, $16 \mathrm{~h}$ at reflux; Scheme 3). Moving from P1 to P4, the number of glycol side chains was increased in a stepwise manner. The resulting crude polymer materials were precipitated in methanol and further 
purified using Soxhlet extractions to remove catalyst residues and low molar mass species. All polymers were soluble in common organic solvents such as chloroform and THF. Numberaveraged molar masses $\left(M_{n}\right)$ as obtained by analytical SEC were 9, 10, 17 and $22 \mathrm{~kg} \mathrm{~mol}^{-1}$ for $\mathbf{P 1}, \mathbf{P 2}, \mathbf{P 3}$ and $\mathbf{P 4}$, respectively (Table 1 ).
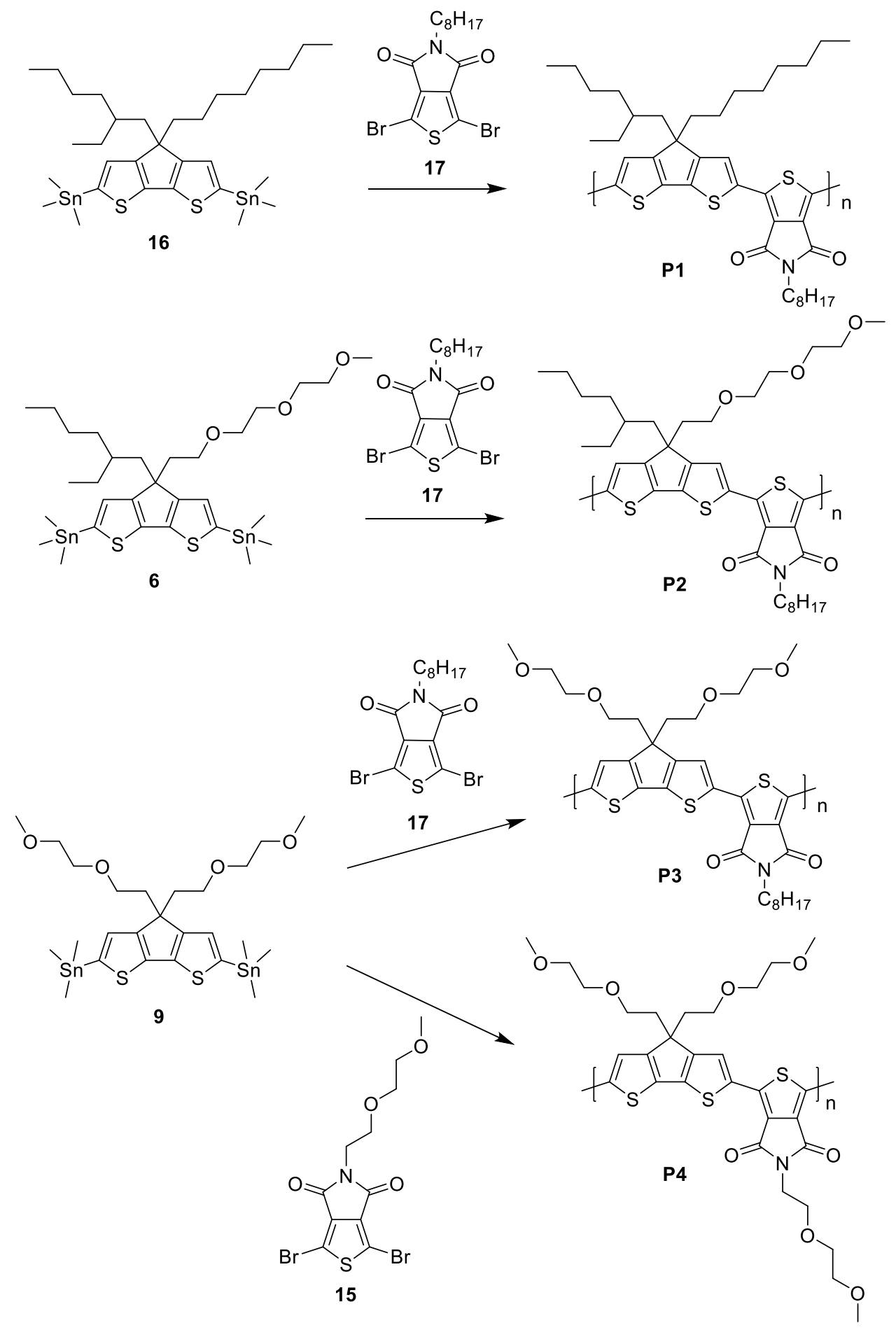

Scheme 3. P(CPDT-alt-TPD) copolymer synthesis by Stille cross-coupling (similar reaction conditions were used for all polymerizations: 2 mol\% $\mathrm{Pd}_{2} \mathrm{dba}_{3}, 8$ mol\% $\mathrm{P}(o \text {-tol })_{3}$, toluene/DMF 5/1, $16 \mathrm{~h}$ at reflux).

To analyze the exact chemical composition of the polymers, MALDI-TOF (matrix-assisted laser desorption ionization time-of-flight) mass spectrometry was performed. The spectrum of P4 
(Figure S1) clearly reveals the expected alternating copolymer structure, but also the occurrence of homo-coupling species resulting from side reactions in the Stille polycondensation. ${ }^{45-47}$ Furthermore, when looking in more detail at the peak distribution (Figure S2), especially methyl terminated oligomeric chains are observed. This implies that a methyl shift occurred during the transmetalation step of the Stille cross-coupling, impeding further chain growth. ${ }^{47,48}$

The thermal properties of the novel polymers were evaluated by means of thermogravimetric analysis (TGA) and rapid heat-cool calorimetry (RHC) (Figure S3-S4). TGA showed that all polymers are thermally stable (i.e. they do not lose any mass) up to $300-325^{\circ} \mathrm{C}$. RHC analysis, preferred over regular differential scanning calorimetry (DSC) because of the improved sensitivity to thermal shifts as a result of the fast scanning rate and the low quantities needed, ${ }^{49}$ indicated that $\mathbf{P} \mathbf{1}$ and $\mathbf{P} \mathbf{2}$ show a melting trajectory, whereas $\mathbf{P} \mathbf{3}$ and $\mathbf{P 4}$ do not show any kind of melting behavior up to $300^{\circ} \mathrm{C}$ (Figure S4). Two different explanations can be given for the absence of a melting behavior for P3 and P4: i) the different side chains prevent crystallization, or ii) the melting peak of both polymers is out of range (i.e. above $300{ }^{\circ} \mathrm{C}$, when degradation sets in).

Figure 1 shows the normalized UV-Vis absorption spectra for all polymers in chloroform solution and as thin films. The optical properties are summarized in Table 1. A bathochromatic shift is observed for all polymers when going from solution to thin film, indicating the tendency to aggregate in the solid state. Besides this red-shift, also some peak broadening and an increase of the absorption at approximately $610 \mathrm{~nm}$ (at the expense of the shoulder at 680 $\mathrm{nm}$ ) can be seen. P3 and P4 show the most pronounced peak broadening and strongest tendency to aggregate in the solid state, probably because of the more flexible OEG side chains. ${ }^{24}$ On the other hand, P1 already shows a pronounced shoulder at higher wavelength in solution, while the absorption onset remains almost unaffected in thin film. The optical bandgaps, measured in terms of the onset of absorption in the solid state, are 1.72, 1.66, 1.62 and $1.63 \mathrm{eV}$ for P1, P2, P3 and P4, respectively, showing a progressive decrease in bandgap upon the replacement of alkyl side chains with OEG.

The electrochemical features of the polymers were investigated by cyclic voltammetry (CV) via the onset potentials of the oxidation and reduction (Figure S5-S6). It can be seen that the HOMO energy levels of the polymers gradually shift up from P1 to P4, whereas the LUMO energy levels slightly go down. This results in a decrease of the electrochemical bandgap of the polymers, in agreement with the UV-Vis absorption trend. The shifts in the energy levels can be attributed to the higher chain flexibility of the OEG side chains, resulting in stronger interchain interactions and closer $\pi-\pi$ stacking, as mentioned before for OEG substituted materials. $^{29}$ 

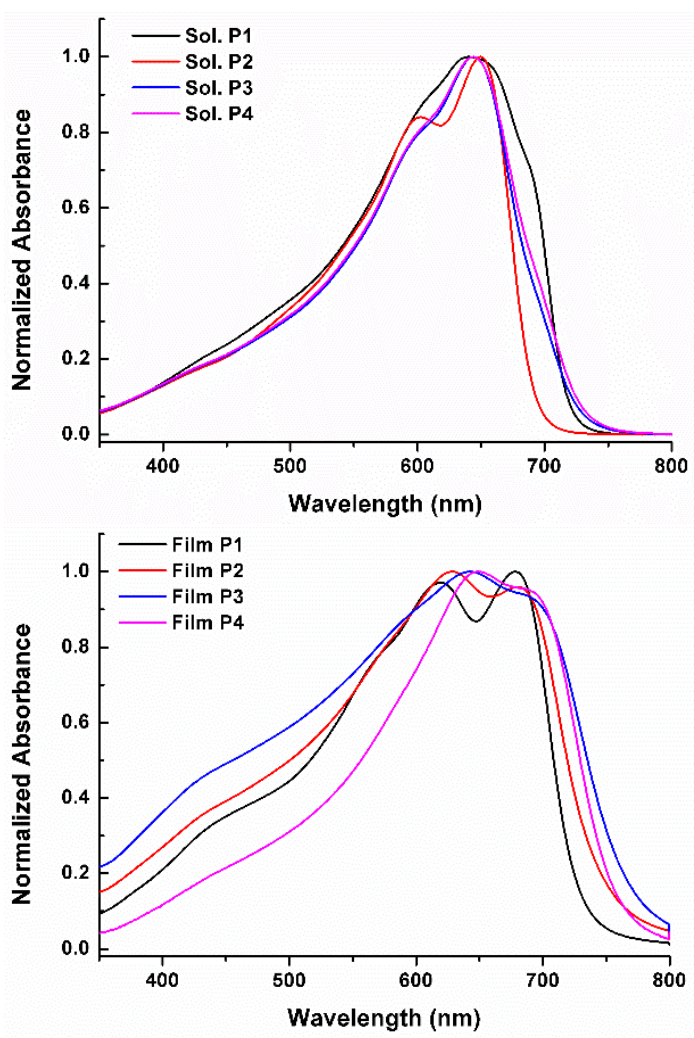

Figure 1. Normalized UV-Vis absorption spectra for P1, P2, P3 and P4 in chloroform solution (top) and thin film (bottom).

Table 1. Characterization data for PCPDTTPD polymers P1-P4.

\begin{tabular}{|c|c|c|c|c|c|c|c|c|c|c|}
\hline & $\begin{array}{c}M_{\mathrm{n}}{ }^{a} / \mathrm{kg} \\
\mathrm{mol}^{-1}\end{array}$ & $\boldsymbol{\theta}$ & $\varepsilon_{r}$ & $\begin{array}{c}\lambda_{\max } \\
\text { film }^{b} / \mathrm{nm}\end{array}$ & $\begin{array}{c}E_{\mathrm{g}, \mathrm{film}}{ }^{c} / \\
\mathrm{eV}\end{array}$ & $\begin{array}{c}E_{\mathrm{ox}}{ }^{d} / \\
\mathrm{eV}\end{array}$ & $\begin{array}{c}E_{\text {red }}^{d} / \\
\mathrm{eV}\end{array}$ & $\begin{array}{c}E_{\mathrm{g}, \mathrm{cv}}{ }^{e} / \\
\mathrm{eV}\end{array}$ & $\begin{array}{c}E_{\text {номо }} f / \\
\mathrm{eV}\end{array}$ & $\begin{array}{c}E_{\text {Lumo }}{ }^{f} / \\
\text { eV }\end{array}$ \\
\hline P1 & 9 & 1.4 & $3.1 \pm 0.1$ & 677 & 1.72 & 0.58 & -1.61 & 2.19 & -5.54 & -3.35 \\
\hline $\mathbf{P 2}$ & 10 & 1.3 & $3.8 \pm 0.1$ & 627 & 1.66 & 0.48 & -1.51 & 1.98 & -5.44 & -3.46 \\
\hline P3 & 17 & 1.6 & $4.9 \pm 0.1$ & 641 & 1.62 & 0.37 & -1.48 & 1.85 & -5.34 & -3.49 \\
\hline P4 & 22 & 1.6 & $6.3 \pm 0.1$ & 649 & 1.63 & 0.33 & -1.41 & 1.74 & -5.30 & -3.56 \\
\hline
\end{tabular}

${ }^{a}$ Measured by SEC at $40{ }^{\circ} \mathrm{C}$ in THF. ${ }^{b}$ Films were prepared by drop-casting a solution of the polymer onto a quartz disc. ${ }^{c}$ Optical bandgap, determined by the onset of the solid-state UV-Vis spectrum. ${ }^{d}$ Onset potential vs. $\mathrm{Fc} / \mathrm{Fc}^{+}$. ${ }^{e}$ Electrochemical bandgap. $f$ Determined from the onset of oxidation/reduction in CV.

\section{Dielectric constant analysis}

The dielectric constants of the semiconducting polymers were evaluated by means of impedance spectroscopy measurements on ITO/PEDOT:PSS/polymer/AI sandwich structures. The samples consisted of a glass substrate with four ITO areas acting as the bottom electrode, a PEDOT:PSS layer, a spin-cast sample polymer layer acting as the dielectric and four 
evaporated aluminum contacts as the top electrode. Varying the film thickness of the polymer layer was achieved by changing the spin-coating conditions in such a way that thicknesses between 100 and $150 \mathrm{~nm}$ were obtained for each material. The examined frequencies ranged from $100 \mathrm{~Hz}$ to $1 \mathrm{MHz}$ and the acquired data were fitted to model the response of the equivalent circuit of a real capacitor - i.e. resistance $R_{s}$ in series with parallel circuit of ideal capacitor $C$ and parallel resistance $R_{p}$ - with less than 1\% error (Figure S7 and S8). Table 1 and Figure 2 list the obtained $\varepsilon_{r}$ values of the pure polymers along with their errors $(0.1$ for all tested capacitors). During the impedance measurements of various capacitors, very small deviations were obtained, resulting in reliable values for $\varepsilon_{\mathrm{r}}$. There is a clear trend of increasing $\varepsilon_{\mathrm{r}}$ upon addition of the OEG chains on the polymer backbone. The reference polymer $\mathbf{P} \mathbf{1}$ has a 'standard' $\varepsilon_{r}$ of $3.1 \pm 0.1$, characteristic for conjugated polymers bearing regular alkyl side chains. Upon the gradual addition of glycol chains, $\varepsilon_{r}$ increases in a stepwise fashion, to $3.8 \pm 0.1$ for $\mathbf{P 2}$ and $4.9 \pm 0.1$ for $\mathbf{P 3}$, and reaching a maximum of $6.3 \pm 0.1$ for polymer P4 bearing 3 OEG chains. Such a substantial increase of the dielectric constant can be attributed to the enhanced $\pi-\pi$ stacking and the higher flexibility of the glycol substituents, which enable a fast change in the direction of the dipoles, ${ }^{26-29}$ rendering $\mathbf{P 4}$ one of the push-pull polymers with the highest $\varepsilon_{\mathrm{r}}$ values reported thus far. ${ }^{33}$

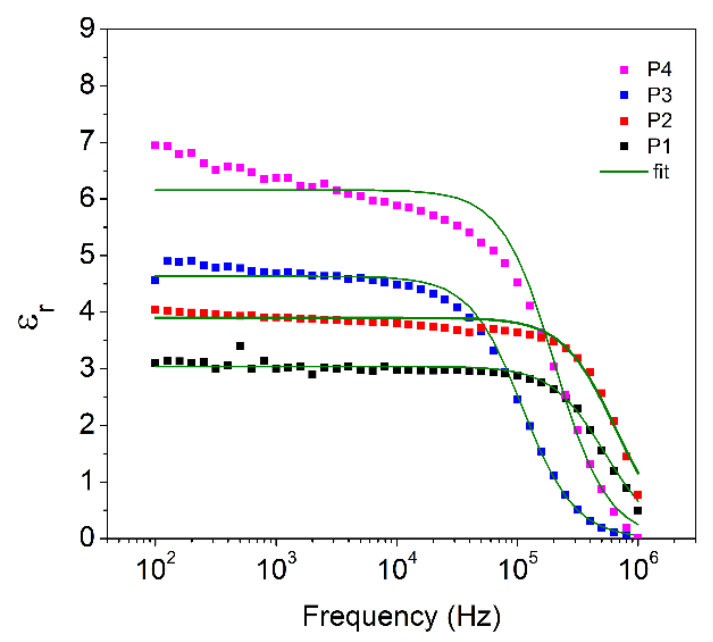

Figure 2. Dielectric constants of polymers P1-P4 plotted vs. frequency.

\section{OPV device fabrication and analysis}

To evaluate the influence of the side chain modification and the dielectric constant enhancement on the device efficiency of organic solar cells encompassing these materials, the four polymers were blended with [70]PCBM and applied as active layers in BHJ polymer solar cells with a traditional device architecture (glass/ITO/PEDOT:PSS/active layer/Ca/Al). The photovoltaic performances of all polymers are summarized in Table 2 (with additional data in Table S1). First of all, the devices were optimized by targeting optimal layer thicknesses and varying the donor:acceptor ratios (from 1:1.5 to 1:3). The photoactive layer thicknesses affording maximum PCEs depend on the polymer material. The devices based on P1 and P2 showed optimal layer thicknesses of 70 and $90 \mathrm{~nm}$, respectively, whereas the solar cells made from P3 and P4 afforded the highest efficiencies for layers around $120 \mathrm{~nm}$. This might be related to the higher $\varepsilon_{r}$ values for these materials, which should in principle reduce 
recombination processes in the active layer blend. The polymer to [70]PCBM weight ratios showed an optimum at 1:1.5 or 1:2, depending on the polymer material. Different processing (co)solvents were then tested for acquiring favorable nanostructured blend morphologies. All polymers exhibited different optimal solvent systems (Table 2). P1 showed the best photovoltaic properties $\left(J_{\mathrm{sc}}=8.29 \mathrm{~mA} \mathrm{~cm}^{-2}, V_{\mathrm{oc}}=0.82 \mathrm{~V}, \mathrm{FF}=0.49\right.$; Table 2) when processed from chlorobenzene without any additive, resulting in a best PCE of 3.3\%. This efficiency is very similar to what was achieved before for an analogous PCPDTTPD polymer (bearing two 2-ethylhexyl side chains on the CPDT unit and the same octyl-substituted TPD; PCE $=3.5 \%){ }^{34}$

Table 2. OPV device parameters for the BHJ polymer solar cells based on P1-P4 (in combination with [70]PCBM).

\begin{tabular}{|c|c|c|c|c|c|c|c|}
\hline Polymer & Solvent $^{a}$ & Ratio & Additive & $V_{\text {oc }} / \mathrm{V}$ & $J_{s c} / \mathrm{mA} \mathrm{cm}^{-2}$ & $\mathbf{F F}$ & $\mathrm{PCE}^{c} / \%$ \\
\hline P1 & CB & $1: 2$ & / & 0.82 & 8.29 & 0.49 & $\begin{array}{c}3.30 \\
(2.88)\end{array}$ \\
\hline P2 & ODCB & $1: 2$ & / & 0.78 & 8.77 & 0.46 & $\begin{array}{c}3.14 \\
(2.91)\end{array}$ \\
\hline P3 & ODCB & $1: 1.5$ & $2 \% \mathrm{DIO}^{b}$ & 0.64 & 13.01 & 0.53 & $\begin{array}{c}4.42 \\
(4.31)\end{array}$ \\
\hline P3 & Anisole & $1: 1.5$ & $2 \% \mathrm{DIO}^{b}$ & 0.64 & 10.91 & 0.57 & $\begin{array}{c}3.97 \\
(3.88)\end{array}$ \\
\hline P4 & ODCB & $1: 2$ & $1 \% \mathrm{DIO}^{b}$ & 0.62 & 11.91 & 0.51 & $\begin{array}{c}3.75 \\
(3.72)\end{array}$ \\
\hline P4 & Anisole & $1: 2$ & $1 \% \mathrm{DIO}^{b}$ & 0.60 & 11.04 & 0.53 & $\begin{array}{c}3.48 \\
(3.33)\end{array}$ \\
\hline
\end{tabular}

The substitution of one CPDT alkyl side chain for a tri(ethylene glycol) substituent in P2 afforded no real enhancement of the OPV characteristics and very similar average efficiencies were achieved for $\mathbf{P 1}$ and $\mathbf{P 2}$ (Table 2). However, a further increase of the OEG/alkyl ratio in P3 did result in an increased performance, with a best device efficiency of $4.4 \%\left(J_{s c}=13.01\right.$ $\mathrm{mA} \mathrm{cm}{ }^{-2}, V_{\mathrm{oc}}=0.64 \mathrm{~V}, \mathrm{FF}=0.53$; Table 2, Figure 3). As anticipated, the output parameter which is influenced most is the short-circuit current density, increasing from $\sim 8$ to $13 \mathrm{~mA} \mathrm{~cm}{ }^{-2}$. This can tentatively be attributed to the enhanced dielectric constant of the donor material, resulting in a more efficient charge generation because of the lower binding energy of the photogenerated excitons. The fill factor is also slightly higher, which could be due to diminished recombination. External quantum efficiencies were measured for all polymer solar cells to investigate the photoresponse (Figure 4). All current densities obtained from the integration of the EQE spectra are within $5 \%$ of the $J_{s c}$ values. For the device based on $\mathbf{P 3}$, an enhancement over the whole wavelength range is seen, with a maximum up to $70 \%$ at lower wavelengths. Remarkably, the best performing P3:[70]PCBM device showed a larger contribution at $\sim 300-550 \mathrm{~nm}$ as compared to the other polymer devices, boosting the photocurrent. On the other hand, a drastic decrease of the open-circuit voltage (by $0.18 \mathrm{~V}$ as compared to P1) was observed as well, limiting the device efficiency. Finally, further substitution of a di(ethylene glycol) substituent on the TPD units in P4 did not result in an 
improved device efficiency, although this material still performs better than the reference polymer $\mathbf{P 1}$, especially due to a higher $J_{s c}$, whereas the $V_{\text {oc }}$ dropped even further. The decrease in $V_{\text {oc }}$ when moving from $\mathbf{P 1}$ to $\mathbf{P 4}$ can be correlated to the upward shift in the HOMO levels of the polymers upon replacement of the alkyl side chains by more flexible OEG substituents (Table 1, 2).

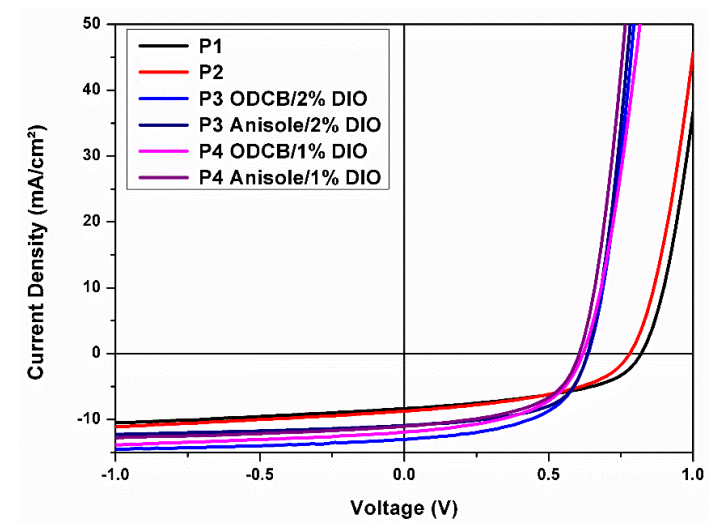

Figure 3. $\mathrm{J}-\mathrm{V}$ curves for the best polymer solar cells based on P1-P4.

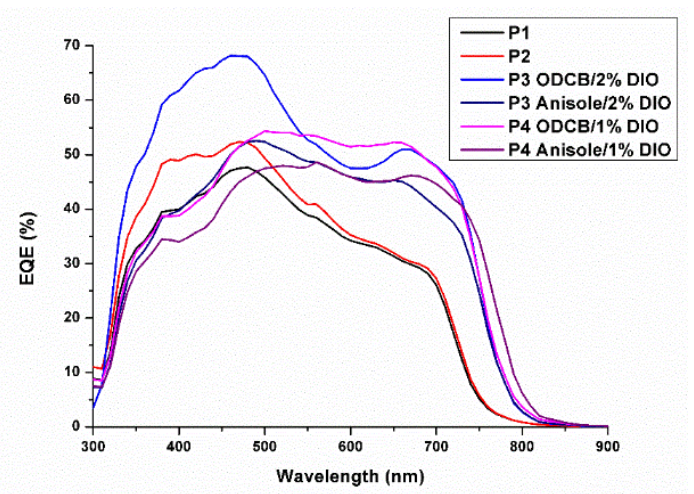

Figure 4. EQE spectra for the best polymer solar cells based on P1-P4.

Because of the higher polarity of (in particular) polymers P3 and P4, alternative nonhalogenated solvent systems were also studied to reduce the exposure to toxic solvents, of high relevance for industrial upscaling by roll-to-roll manufacturing. Comparable results were obtained for both P3 and P4 when processed from anisole with 1,8-diiodoctane as a cosolvent. Slightly lower short-circuit currents, but higher fill factors, were measured, illustrating the beneficial green solvent processability of high- $\varepsilon_{r}$ organic semiconductors.

To shed more light on the origin of the improved device performance achieved for high- $\varepsilon_{\mathrm{r}}$ polymers P3 and P4, especially the higher $J_{s c}$ values, the hole mobilities of the polymer materials were determined from OFET measurements and the BHJ active layer morphology was studied by means of atomic force microscopy (AFM) in tapping mode. All polymers displayed similar hole mobilities ( $\mu_{\text {hole }}=9.910^{-5}, 4.410^{-5}, 5.410^{-5}$ and $2.110^{-5} \mathrm{~cm}^{2} / \mathrm{Vs}$ for P1, P2, P3 and P4, respectively). These results are in accordance with literature observations wherein organic semiconductors with OEG side chains exhibit similar hole mobilities as their hydrocarbon counterparts. ${ }^{19,20,24,26}$ This implies that the higher $J_{s c}$ values cannot simply be attributed to enhanced hole mobilities. The AFM topographic images of the best BHJ polymer solar cells are shown in Figure 5. The blends consisting of either P1 or P2 in combination with 
[70]PCBM show a very fine, fully intermixed morphology, with almost no distinct phase separation. On the other hand, the active layers based on P3 and P4 display a more rough morphology, both when processed from ortho-dichlorobenzene and anisole. Regarding the higher device performances of these solar cells, it seems important that a fine intermixing of the donor and acceptor is achieved, but also enriched domains of the pure materials are required to create efficient percolation pathways for the charge carriers.

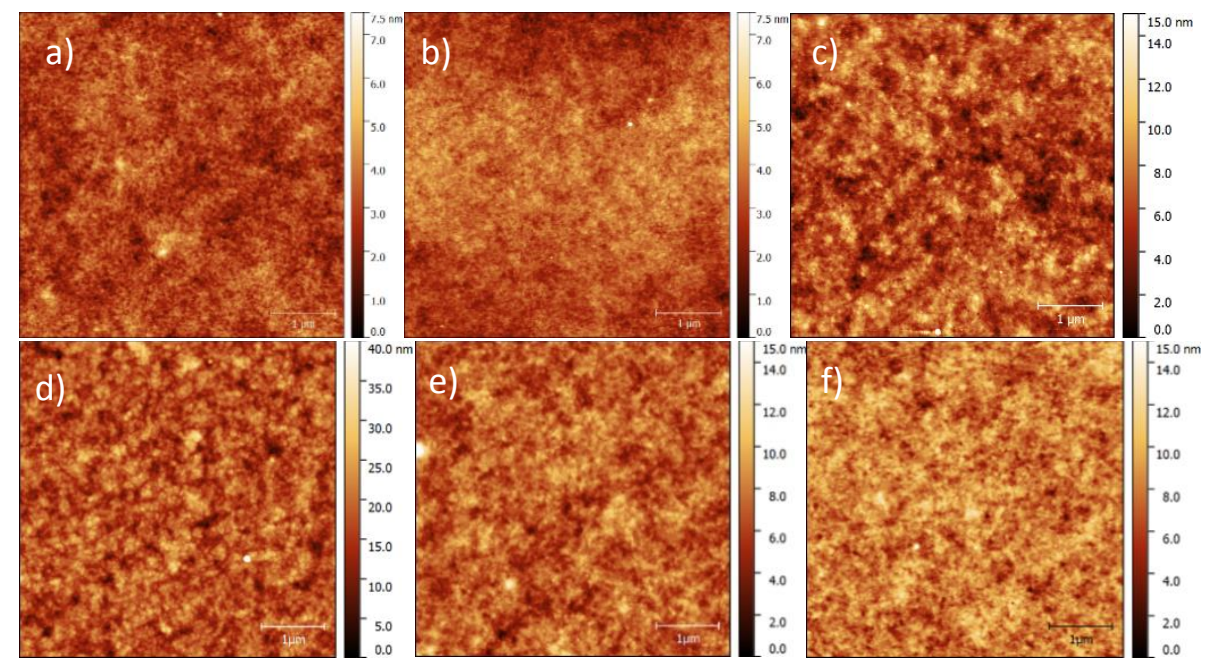

Figure 5. AFM images $(5.0 \times 5.0 \mu \mathrm{m})$ of the active layer blends (affording the best OPV devices) based on [70]PCBM in combination with a) P1 (CB), b) P2 (ODCB), c) P3 (ODCB + 2\% DIO), d) P3 (anisole + $2 \%$ DIO), e) P4 (ODCB + 1\% DIO) and f) P4 (anisole + 1\% DIO).

\section{Conclusions}

In summary, four new PCPDTTPD-type donor-acceptor copolymers were designed, synthesized and characterized with the aim to enhance their dielectric properties. Glycol side chains were chosen to increase the polarizability of the resulting polymers, which is directly correlated to the permittivity. A clear trend in $\varepsilon_{r}$ was observed when gradually replacing the alkyl side chains with oligo(ethylene glycol) moieties, resulting in a PCPDTTPD-type low bandgap polymer with an $\varepsilon_{r}$ up to 6.3 , more than doubled compared to the reference alkyl substituted polymer. This is a record dielectric constant for conjugated polymer materials in our hands. ${ }^{33}$ Higher short-circuit currents were obtained in polymer solar cells prepared from the most 'glycolated' polymers. Despite the fact that a simultaneous decrease in open-circuit voltage (as a result of the higher HOMO energy levels) limits the final efficiency improvement, an increased power conversion efficiency was achieved, which can likely partly be attributed to the higher dielectric constant of the donor material, facilitating charge extraction. Moreover, an alternative halogen-free processing solvent (anisole) was also used and similar device parameters were obtained, a promising result in terms of sustainability. The enhanced dielectric properties and improved device characteristics illustrate the high potential of ethylene glycol-based side chains as alternatives to the widely used solubilizing alkyl side chains. Current work focuses on further enhancement of the dielectric properties of conjugated polymer materials and their application in OPD and PV (organic as well as hybrid perovskite) devices. Moreover, some efforts are done to translate these results to a system 
where a high- $\varepsilon_{r}$ donor material (e.g. P4) is combined with a high- $\varepsilon_{r}$ (glycolated) electron acceptor. The ultimate goal remains, however, to use a high- $\varepsilon_{r}$ organic semiconductor in an efficient homojunction (i.e. single layer) PV device.

\section{Conflicts of interest}

There are no conflicts of interest to declare.

\section{Acknowledgements}

This work was supported by the Research Foundation - Flanders (FWO) (projects G.0415.14N and G.0B67.15N). J. Brebels acknowledges the former Agency for Innovation by Science and Technology in Flanders (IWT; now FWO) for his PhD grant. E. Douvogianni and J. C. Hummelen publish this work as members of the FOM Focus Group "Next Generation Organic Photovoltaics", participating in the Dutch Institute for Fundamental Energy Research (DIFFER). The authors are also grateful to B. Van Mele and M. Defour for thermal analysis and H. Penxten for cyclic voltammetry.

\section{Electronic supplementary information}

${ }^{1} \mathrm{H}$ and ${ }^{13} \mathrm{C}$ NMR spectra of monomers and polymers, MALDI-TOF mass spectra, thermal analysis and CV figures, impedance spectroscopy data and figures, and additional solar cell optimization data can be found in the supplementary information.

\section{Experimental section}

\section{Materials and methods}

(4-(2-Ethylhexyl)-4-octyl-4H-cyclopenta[2,1-b:3,4-b']dithiophene-2,6-diyl)bis(trimethylstannane) (16) was prepared according to a literature procedure. ${ }^{41}$ All other reagents and chemicals were obtained from commercial sources and used without further purification. Solvents were dried by a solvent purification system (MBraun, MB-SPS-800) equipped with alumina columns.

Preparative (recycling) size exclusion chromatography was performed on a JAI LC-9110 NEXT system equipped with JAIGEL $1 \mathrm{H}$ and $2 \mathrm{H}$ columns (eluent $\mathrm{CHCl}_{3}$, flow rate $3.5 \mathrm{~mL} \mathrm{~min}^{-1}$ ). NMR chemical shifts $\left(\delta\right.$, in ppm) were determined relative to the residual $\mathrm{CHCl}_{3}(7.26 \mathrm{ppm})$ absorption or the ${ }^{13} \mathrm{C}$ resonance shift of $\mathrm{CDCl}_{3}(77.16 \mathrm{ppm})$. High resolution ESI-MS was performed using a LTQ Orbitrap Velos Pro mass spectrometer equipped with an atmospheric pressure ionization source operating in the nebulizer assisted electrospray mode. The instrument was calibrated in the $\mathrm{m} / \mathrm{z}$ range 220-2000 using a standard solution containing caffeine, MRFA and Ultramark 1621. MALDI-TOF mass spectra were recorded on a Bruker Daltonics Ultraflex II Tof/Tof. A total of $1 \mu \mathrm{L}$ of the matrix solution (4 $\mathrm{mg} \mathrm{mL}^{-1}$ DTCB (trans-2[3-(4-tert-butylphenyl)-2-methyl-2-propenylidene]malononitrile) in $\mathrm{CHCl}_{3}$ ) was spotted onto an MTP Anchorchip 600/384 MALDI plate. The spot was allowed to dry and $1 \mu \mathrm{L}$ of the analyte solution ( $0.5 \mathrm{mg} \mathrm{mL}^{-1}$ in chloroform) was spotted on top of the matrix. UV-Vis absorption spectroscopy measurements were performed on a VARIAN Cary 5000 UV-Vis 
spectrophotometer at a scan rate of $600 \mathrm{~nm} \mathrm{~min}$. The films for the UV-Vis absorption measurements were prepared by drop casting a solution of the respective polymer in chloroform on a quartz substrate. The solid-state UV-Vis absorption spectra were used to estimate the optical bandgaps (from the wavelength at the intersection of the tangent line drawn at the low energy side of the absorption spectrum with the baseline: $E_{\mathrm{g}}(\mathrm{eV})=$ $1240 /($ wavelength in $\mathrm{nm}$ )). Analysis of the molar masses and molar mass distributions of the polymers was performed on a Tosoh EcoSEC System, comprising of an autosampler, a PSS guard column SDV $(50 \times 7.5 \mathrm{~mm})$ followed by three PSS SDV analytical linear XL columns ( 5 $\mu \mathrm{m}, 300 \times 7.5 \mathrm{~mm}$ ), and a UV-detector using THF as the eluent at $40{ }^{\circ} \mathrm{C}$ with a flow rate of 1.0

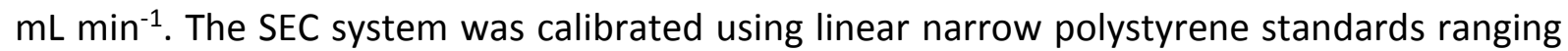
from 474 to $7.5 \times 10^{6} \mathrm{~g} \mathrm{~mol}^{-1}\left(\mathrm{~K}=14.1 \times 10^{-5} \mathrm{dL} \mathrm{g}^{-1}\right.$ and $\left.\alpha=0.70\right)$. Electrochemical measurements (cyclic voltammetry) were performed with an Eco Chemie Autolab PGSTAT 30 potentiostat/galvanostat using a three-electrode microcell with a platinum working electrode, a platinum counter electrode and a $\mathrm{Ag} / \mathrm{AgNO}_{3}$ reference electrode (silver wire dipped in a solution of $0.01 \mathrm{M} \mathrm{AgNO}_{3}$ and $0.1 \mathrm{M} \mathrm{NBu}_{4} \mathrm{PF}_{6}$ in anhydrous acetonitrile). The reference electrode was calibrated against ferrocene/ferrocenium as an external standard. Samples were prepared by dip coating the platinum working electrode in the respective polymer solutions (also used for the solid-state UV-Vis measurements). The CV measurements were done on the resulting films with $0.1 \mathrm{M} \mathrm{NBu}_{4} \mathrm{PF}_{6}$ in anhydrous acetonitrile as electrolyte solution. To prevent air from entering the system, the experiments were carried out under a curtain of argon. Cyclic voltammograms were recorded at a scan rate of $100 \mathrm{mV} \mathrm{s}^{-1}$. For the conversion of $\mathrm{V}$ to $\mathrm{eV}$, the onset potentials of the first oxidation/reduction peaks were used and referenced to ferrocene/ferrocenium, which has an ionization potential of $-4.98 \mathrm{eV} v s$. vacuum. This correction factor is based on a value of $0.31 \mathrm{eV}$ for $\mathrm{Fc} / \mathrm{Fc}^{+}$vs. SCE ${ }^{50}$ and a value

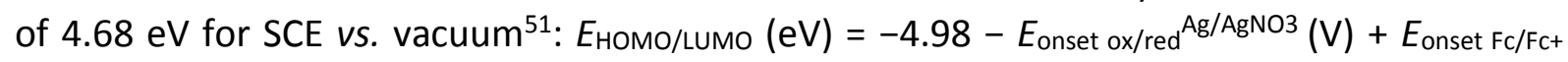
$\mathrm{Ag} / \mathrm{AgNO} 3(\mathrm{~V})$. The accuracy of measuring redox potentials by $\mathrm{CV}$ is $\sim 0.01-0.02 \mathrm{~V}$. Reproducibility can be less because the potentials depend on concentration and temperature. Rapid heat-cool calorimetry (RHC) experiments were performed on a prototype RHC of TA Instruments, equipped with liquid nitrogen cooling and specifically designed for operation at high scanning rates. RHC measurements were performed at $500 \mathrm{~K} \mathrm{~min}^{-1}$ (after cooling at $20 \mathrm{~K}$ $\mathrm{min}^{-1}$ ) using aluminum crucibles filled with samples of $200-250 \mu \mathrm{g}$, using helium $(10 \mathrm{~mL} \mathrm{~min}-$ $\left.{ }^{1}\right)$ as a purge gas. TGA experiments were performed at $20 \mathrm{~K} \mathrm{~min}^{-1}$ in platinum crucibles on a TA Instruments Q5000 TGA using nitrogen $\left(50 \mathrm{~mL} \mathrm{~min}^{-1}\right)$ as purge gas.

\section{Materials synthesis and characterization}

3,3'-Dibromo-2,2'-bithiophene (2). ${ }^{42}$ 3-Bromothiophene (32.6 g, $200 \mathrm{mmol}$ ) was dissolved in dry THF and LDA (100 mL, $200 \mathrm{mmol}$ ) was added dropwise at $-78{ }^{\circ} \mathrm{C}$ under inert atmosphere. The solution was then stirred for $1.5 \mathrm{~h}$ at $-78^{\circ} \mathrm{C}$. $\mathrm{CuCl}_{2}(29.6 \mathrm{~g}, 220 \mathrm{mmol})$ was added and the reaction mixture was stirred overnight at room temperature. The reaction was quenched with a $1 \mathrm{M} \mathrm{HCl}$ solution, dichloromethane was added and the organic phase was washed with water $(2 \times)$, dried over anhydrous $\mathrm{MgSO}_{4}$ and filtered. The solvent was removed under reduced pressure and the crude product was purified by flash chromatography (silica, $n$-hexane: dichloromethane, 50:50) and Kugelrohr distillation $\left(2 \times 10^{-2}\right.$ mbar, $\left.110{ }^{\circ} \mathrm{C}\right)$. After recrystallization from ethanol, 3,3'-dibromo-2,2'-bithiophene was obtained as white crystals (22.0 g, 72\%). ${ }^{1} \mathrm{H}$ NMR (400 MHz, $\left.\mathrm{CDCl}_{3}\right), \delta(\mathrm{ppm}): 7.41$ (d, J=5.4 Hz, $\left.2 \mathrm{H}\right), 7.08(\mathrm{~d}, J=5.4 \mathrm{~Hz}$, $2 \mathrm{H})$. 
4H-Cyclopenta[2,1-b:3,4-b']dithiophen-4-one (3). ${ }^{43}$ 3,3'-Dibromo-2,2'-bithiophene (10.0 g, $30.8 \mathrm{mmol}$ ) was dissolved in dry diethyl ether and the solution was cooled to $-78{ }^{\circ} \mathrm{C}$ under inert atmosphere. $n$-BuLi $(27.2 \mathrm{~mL}, 67.9 \mathrm{mmol})$ was added dropwise to the solution and after stirring the solution for $1 \mathrm{~h}$ at $-78{ }^{\circ} \mathrm{C}$, dimethylcarbamoyl chloride $(3.1 \mathrm{~mL}, 33.9 \mathrm{mmol}$ ) was added dropwise. The solution was then allowed to stir overnight at room temperature. Diethyl ether was added and the organic phase was washed with water $(2 x)$, dried over anhydrous $\mathrm{MgSO}_{4}$ and filtered. The solvent was removed under reduced pressure. To obtain a pure product, recrystallization from ethanol was performed to obtain $4 H$-cyclopenta[2,1-b:3,4$b^{\prime}$ ]dithiophen-4-one as red crystals (4.5 g, 76\%). $\left.{ }^{1} \mathrm{H} \mathrm{NMR} \mathrm{(400} \mathrm{MHz,} \mathrm{CDCl}_{3}\right), \delta(\mathrm{ppm}): 7.04$ (d, J $=4.8 \mathrm{~Hz}, 2 \mathrm{H}), 7.00(\mathrm{~d}, J=4.8 \mathrm{~Hz}, 2 \mathrm{H})$.

4-(2-Ethylhexylidene)-4H-cyclopenta[2,1-b:3,4-b']dithiophene (4). ${ }^{41}$ (2-Ethylhexyl)triphenylphosphonium bromide $(12.26 \mathrm{~g}, 32.7 \mathrm{mmol}$ ) was dissolved in dry THF and the solution was cooled to $-78{ }^{\circ} \mathrm{C}$ under inert atmosphere. $n$-BuLi $(10.8 \mathrm{~mL}, 11.7 \mathrm{mmol})$ was added dropwise and the solution was allowed to stir for $30 \mathrm{~min}$ at this temperature. $4 \mathrm{H}$-cyclopenta[2,1-b:3,4$b^{\prime}$ ] dithiophen-4-one $(4.00 \mathrm{~g}, 20.9 \mathrm{mmol})$ was dissolved in dry diethyl ether $(30 \mathrm{~mL})$ and added to the previously prepared solution. The reaction mixture was then stirred overnight at room temperature. Diethyl ether was added and the organic phase was washed with water $(2 x)$, dried over anhydrous $\mathrm{MgSO}_{4}$ and filtered. The crude product was purified by column chromatography (silica, eluent petroleum ether) to yield 4-(2-ethylhexylidene)-4Hcyclopenta[2,1-b:3,4- $\left.b^{\prime}\right]$ dithiophene as a yellow solid (4.6 g, 77\%). ${ }^{1} \mathrm{H} \mathrm{NMR}\left(400 \mathrm{MHz}, \mathrm{CDCl}_{3}\right)$, $\delta(\mathrm{ppm}): 7.28(\mathrm{~d}, J=4.9 \mathrm{~Hz}, 2 \mathrm{H}), 7.15(\mathrm{~d}, J=4.9 \mathrm{~Hz}, 2 \mathrm{H}), 6.16(\mathrm{~d}, J=10.5 \mathrm{~Hz}, 1 \mathrm{H}), 2.94-2.83(\mathrm{~m}$, $1 \mathrm{H}), 1.72-1.58(\mathrm{~m}, 2 \mathrm{H}), 1.50-1.39(\mathrm{~m}, 2 \mathrm{H}), 1.33-1.25(\mathrm{~m}, 4 \mathrm{H}), 0.92(\mathrm{t}, J=7.4 \mathrm{~Hz}, 3 \mathrm{H}), 0.85(\mathrm{t}, J$ $=7.0 \mathrm{~Hz}, 3 \mathrm{H})$.

\section{4-(2-Ethylhexyl)-4-(2-(2-(2-methoxyethoxy)ethoxy)ethyl)-4H-cyclopenta[2,1-b:3,4-b']di-}

thiophene (5). A solution of 4-(2-ethylhexylidene)-4H-cyclopenta[2,1-b:3,4- $\left.b^{\prime}\right]$ dithiophene (0.33 g, $1.14 \mathrm{mmol}$ ) and 1-chloro-2-(2-(2-methoxyethoxy)ethoxy)ethane (0.27 g, $1.48 \mathrm{mmol})$ in dry methyl tert-butyl ether (MTBE) was added to a suspension of $\mathrm{LiAlH}_{4}(0.115 \mathrm{~g}, 1.37 \mathrm{mmol})$ in dry MTBE at $60{ }^{\circ} \mathrm{C}$ under inert atmosphere. The reaction was stirred overnight at room temperature. $1 \mathrm{M} \mathrm{HCl}$ solution and dichloromethane were added and the organic phase was washed with $\mathrm{NaHCO}_{3}$ and water (2x), dried over anhydrous $\mathrm{MgSO}_{4}$ and filtered. The crude product was purified by column chromatography (silica, eluent petroleum ether:diethyl ether, 70:30) to obtain 4-(2-ethylhexyl)-4-(2-(2-(2-methoxyethoxy)ethoxy)ethyl)-4H-cyclopenta[2,1$\left.b: 3,4-b^{\prime}\right]$ dithiophene as a pale oil $(0.31 \mathrm{~g}, 62 \%) .{ }^{1} \mathrm{H} \mathrm{NMR}\left(300 \mathrm{MHz}, \mathrm{CDCl}_{3}\right), \delta(\mathrm{ppm}): 7.13(\mathrm{~d}, J$ $=4.9 \mathrm{~Hz}, 2 \mathrm{H}), 6.99-6.88(\mathrm{~m}, 2 \mathrm{H}), 3.61-3.53(\mathrm{~m}, 2 \mathrm{H}), 3.54-3.44(\mathrm{~m}, 4 \mathrm{H}), 3.36(\mathrm{~s}, 3 \mathrm{H}), 3.32(\mathrm{t}, J$ $=4.8 \mathrm{~Hz}, 2 \mathrm{H}), 2.94(\mathrm{t}, J=7.5 \mathrm{~Hz}, 2 \mathrm{H}), 2.22(\mathrm{t}, J=7.7 \mathrm{~Hz}, 2 \mathrm{H}), 1.96-1.80(\mathrm{~m}, 2 \mathrm{H}), 1.11-0.78(\mathrm{~m}$, $8 \mathrm{H}), 0.75(\mathrm{t}, J=6.9 \mathrm{~Hz}, 3 \mathrm{H}), 0.67-0.52(\mathrm{~m}, 4 \mathrm{H}) .{ }^{13} \mathrm{C} \mathrm{NMR}\left(75 \mathrm{MHz}, \mathrm{CDCl}_{3}\right), \delta(\mathrm{ppm}): 157.1,157.0$, 136.8, 124.6, 122.0, 72.0, 70.7, 70.6, 70.1, 67.8, 59.1, 51.3, 42.3, 38.6, 35.1, 34.2, 28.7, 27.3, 22.8, 14.2, 10.8. HRMS (ESI+): calcd. for $\mathrm{C}_{24} \mathrm{H}_{36} \mathrm{O}_{3} \mathrm{~S}_{2}[\mathrm{M}+\mathrm{H}]^{+}: 437.2186$, measured: 437.2168 .

\section{(4-(2-Ethylhexyl)-4-(2-(2-(2-methoxyethoxy)ethoxy)ethyl)-4H-cyclopenta[2,1-b:3,4-b']di-}

thiophene-2,6-diyl)bis(trimethylstannane) (6). 4-(2-Ethylhexyl)-4-(2-(2-(2-methoxyethoxy)ethoxy)ethyl)-4H-cyclopenta[2,1-b:3,4- $b^{\prime}$ ]dithiophene $(0.30 \mathrm{~g}, 0.687 \mathrm{mmol})$ was dissolved in dry THF under inert atmosphere. The reaction mixture was protected from light and cooled down to $-78^{\circ} \mathrm{C}$ before $n$-BuLi $(1.9 \mathrm{~mL}, 4.8 \mathrm{mmol})$ was added dropwise to the solution and the 
reaction mixture was stirred for another $30 \mathrm{~min}$ under inert atmosphere at $-78{ }^{\circ} \mathrm{C}$. Trimethyltin chloride $(5.5 \mathrm{~mL}, 5.5 \mathrm{mmol})$ was added and the reaction mixture was stirred overnight at room temperature. Diethyl ether was added and the organic phase was washed with water (2x), dried over anhydrous $\mathrm{MgSO}_{4}$ and filtered. Further purification was done by recycling prep-SEC $\left(\mathrm{CHCl}_{3}\right)$ to yield (4-(2-ethylhexyl)-4-(2-(2-(2-methoxyethoxy)ethoxy)ethyl)4H-cyclopenta[2,1-b:3,4-b']dithiophene-2,6-diyl)bis(trimethylstannane) (0.28 g, 54\%). ${ }^{1} \mathrm{H}$ NMR $\left(400 \mathrm{MHz}, \mathrm{CDCl}_{3}\right), \delta(\mathrm{ppm}): 6.98-6.90(\mathrm{~m}, 2 \mathrm{H}), 3.59-3.55(\mathrm{~m}, 2 \mathrm{H}), 3.52-3.47(\mathrm{~m}, 4 \mathrm{H}), 3.35(\mathrm{~s}$, $3 \mathrm{H}), 3.34-3.31(\mathrm{~m}, 2 \mathrm{H}), 2.99-2.93(\mathrm{t}, J=7.6 \mathrm{~Hz}, 2 \mathrm{H}), 2.23(\mathrm{t}, J=7.7 \mathrm{~Hz}, 2 \mathrm{H}), 1.92-1.78(\mathrm{~m}, 2 \mathrm{H})$, $1.03-0.84(\mathrm{~m}, 8 \mathrm{H}), 0.73(\mathrm{t}, J=7.0 \mathrm{~Hz}, 3 \mathrm{H}), 0.68-0.55(\mathrm{~m}, 4 \mathrm{H}), 0.44-0.29(\mathrm{~m}, 18 \mathrm{H})$.

4,4-Bis(2-(2-methoxyethoxy)ethyl)-4H-cyclopenta[2,1-b:3,4-b']dithiophene (8). $4 H$ Cyclopenta[2,1-b:3,4- $\left.b^{\prime}\right]$ dithiophene $\quad(0.200 \quad \mathrm{~g}, \quad 1.12 \mathrm{mmol}), \quad$ 1-chloro-2-(2methoxyethoxy)ethane $(0.621 \mathrm{~g}, 4.48 \mathrm{mmol})$ and $\mathrm{KI}(5.6 \mathrm{mg}, 0.034 \mathrm{mmol})$ were dissolved in DMSO $(20 \mathrm{~mL})$ and $\mathrm{KOH}(0.22 \mathrm{~g}, 3.9 \mathrm{mmol})$ was slowly added in portions at $0{ }^{\circ} \mathrm{C}$. The reaction mixture was stirred overnight at room temperature. Dichloromethane was added and the organic phase was washed with water (2x), dried over anhydrous $\mathrm{MgSO}_{4}$ and filtered. The crude product was purified by column chromatography (silica, eluent petroleum ether:ethyl acetate, 70:30) to yield 4,4-bis(2-(2-methoxyethoxy)ethyl)-4H-cyclopenta[2,1-b:3,4$b^{\prime}$ ddithiophene (0.251 g, 58\%). ${ }^{1} \mathrm{H}$ NMR $\left(400 \mathrm{MHz}, \mathrm{CDCl}_{3}\right), \delta(\mathrm{ppm}): 7.15(\mathrm{~d}, J=4.9 \mathrm{~Hz}, 2 \mathrm{H}), 6.96$ (d, $J=4.9 \mathrm{~Hz}, 2 \mathrm{H}), 3.39-3.36(\mathrm{~m}, 4 \mathrm{H}), 3.31(\mathrm{~s}, 6 \mathrm{H}), 3.31-3.28(\mathrm{~m}, 4 \mathrm{H}), 2.99(\mathrm{t}, J=7.6 \mathrm{~Hz}, 4 \mathrm{H})$, $2.28(\mathrm{t}, J=7.5 \mathrm{~Hz}, 4 \mathrm{H}) .{ }^{13} \mathrm{C} \mathrm{NMR}\left(100 \mathrm{MHz}, \mathrm{CDCl}_{3}\right), \delta(\mathrm{ppm}): 156.5,136.6,125.1,121.8,71.9$, 70.1, 67.7, 59.1, 49.2, 37.7. HRMS (ESI+): calcd. for $\mathrm{C}_{19} \mathrm{H}_{26} \mathrm{O}_{4} \mathrm{~S}_{2}[\mathrm{M}+\mathrm{H}]^{+}: 383.1353$, measured: 383.1344 .

(4,4-Bis(2-(2-methoxyethoxy)ethyl)-4H-cyclopenta[2,1-b:3,4-b']dithiophene-2,6-

diyl)bis(trimethylstannane) (9). 4,4-Bis(2-(2-methoxyethoxy)ethyl)-4H-cyclopenta[2,1-b:3,4$b^{\prime}$ ]dithiophene $(0.247 \mathrm{~g}, 0.644 \mathrm{mmol})$ was dissolved in dry THF under inert atmosphere. The reaction mixture was cooled to $-40{ }^{\circ} \mathrm{C}$ before $n$-BuLi $(1.55 \mathrm{~mL}, 3.87 \mathrm{mmol})$ was added dropwise to the solution and the reaction mixture was stirred for another 30 min under inert atmosphere at $-40^{\circ} \mathrm{C}$. Trimethyltin chloride $(4.2 \mathrm{~mL}, 4.2 \mathrm{mmol})$ was added and the reaction mixture was stirred overnight at room temperature. Diethyl ether was added and the organic phase was washed with water $(2 \times)$, dried over anhydrous $\mathrm{MgSO}_{4}$ and filtered. Further purification was done by recycling prep-SEC $\left(\mathrm{CHCl}_{3}\right)$ to yield (4,4-bis(2-(2methoxyethoxy)ethyl)-4H-cyclopenta[2,1-b:3,4-b']dithiophene-2,6-diyl)bis(trimethylstannane) (0.269 g, 65\%). ${ }^{1} \mathrm{H}$ NMR (400 MHz, $\left.\mathrm{CDCl}_{3}\right), \delta(\mathrm{ppm}): 6.96(\mathrm{~s}, 2 \mathrm{H}), 3.40-3.36(\mathrm{~m}, 4 \mathrm{H}), 3.33-$ $3.30(\mathrm{~m}, 10 \mathrm{H}), 3.00(\mathrm{t}, J=7.6 \mathrm{~Hz}, 4 \mathrm{H}), 2.28(\mathrm{t}, J=7.6 \mathrm{~Hz}, 4 \mathrm{H}), 0.45-0.30(\mathrm{~m}, 18 \mathrm{H})$.

2,5-Dibromothiophene-3,4-dicarboxylic acid (11). Prepared according to a reported procedure. $^{44}$

4,6-Dibromo-1H,3H-thieno[3,4-c]furan-1,3-dione (12). Prepared according to a reported procedure. ${ }^{44}$

2,5-Dibromo-4-carbamoylthiophene-3-carboxylic acid (13). Prepared according to a reported procedure. $^{44}$ 
1,3-Dibromo-4H-thieno[3,4-c]pyrrole-4,6(5H)-dione (14). Prepared according to a reported procedure. ${ }^{44}$

1,3-Dibromo-5-(2-(2-methoxyethoxy)ethyl)-4H-thieno[3,4-c]pyrrole-4,6(5H)-dione (15). $\mathrm{NaH}$ (60\%; $0.19 \mathrm{~g}, 4.76 \mathrm{mmol}$ ) was added slowly to 1,3-dibromo-4H-thieno[3,4-c]pyrrole4,6(5H)-dione (1.14 g, $3.66 \mathrm{mmol})$ in dry DMF under inert atmosphere. The reaction mixture was stirred at room temperature for $1 \mathrm{~h}$ and then added dropwise to a $50{ }^{\circ} \mathrm{C}$ solution of 1bromo-2-(2-methoxyethoxy)ethane $(1.00 \mathrm{~mL}, 7.43 \mathrm{mmol})$ in dry DMF. The reaction mixture was subsequently stirred overnight at room temperature. Dichloromethane was added and the organic phase was washed with water $(2 \times)$, dried over anhydrous $\mathrm{MgSO}_{4}$ and filtered. The solvent was removed under reduced pressure and the residue was purified by column chromatography (silica, eluent $n$-hexane:dichloromethane, 50:50). The solvent was removed under reduced pressure and the crude product was recrystallized from methanol to yield pure 1,3-dibromo-5-(2-(2-methoxyethoxy)ethyl)-4H-thieno[3,4-c]pyrrole-4,6(5H)-dione (0.70 g, 46 \%). ${ }^{1} \mathrm{H}$ NMR (400 MHz, $\mathrm{CDCl}_{3}$ ), $\delta$ (ppm): 3.82 (t, J=5.8 Hz, $\left.2 \mathrm{H}\right), 3.72(\mathrm{t}, J=5.7 \mathrm{~Hz}, 2 \mathrm{H}$ ), 3.66$3.62(\mathrm{~m}, 2 \mathrm{H}), 3.52-3.49(\mathrm{~m}, 2 \mathrm{H}), 3.35(\mathrm{~s}, 3 \mathrm{H}) .{ }^{13} \mathrm{C} \mathrm{NMR}\left(75 \mathrm{MHz}, \mathrm{CDCl}_{3}\right), \delta(\mathrm{ppm}): 160.1,134.6$, 113.1, 71.8, 69.8, 67.5, 59.0, 37.7. HRMS (ESI+): calcd. for $\mathrm{C}_{11} \mathrm{H}_{11} \mathrm{~B}_{\mathrm{r} 2} \mathrm{NO}_{4} \mathrm{~S}[\mathrm{M}+\mathrm{H}]^{+}$: 411.8856, measured: 411.8850 .

1,3-Dibromo-5-octyl-4H-thieno[3,4-c]pyrrole-4,6(5H)-dione (17). Prepared according to a reported procedure. ${ }^{52}$

(4-(2-Ethylhexyl)-4-octyl-4H-cyclopenta[2,1-b:3,4-b']dithiophene-2,6-diyl)bis(trimethylstannane) (16). Prepared according to a reported procedure. ${ }^{41}$

PCPDTTPD P1. General polymerization method: A mixture of (4-(2-ethylhexyl)-4-octyl-4Hcyclopenta[2,1-b:3,4-b']dithiophene-2,6-diyl)bis(trimethylstannane) (16) (139 mg, 0.191 $\mathrm{mmol}$ ) and 1,3-dibromo-5-octyl-4H-thieno[3,4-c]pyrrole-4,6(5H)-dione (17) (80.7 mg, 0.191 $\mathrm{mmol}$ ) was dissolved in dry toluene $(2.5 \mathrm{~mL})$ and dry DMF $(0.5 \mathrm{~mL})$ and the solution was degassed for $20 \mathrm{~min}$. Subsequently, $\mathrm{Pd}_{2}(\mathrm{dba})_{3}(3.48 \mathrm{mg}, 3.8 \mu \mathrm{mol})$ and $\mathrm{P}(\mathrm{o} \text {-tol })_{3}(4.6 \mathrm{mg}, 15.2$ $\mu \mathrm{mol})$ were added and the mixture was stirred overnight at reflux temperature. The resulting crude polymer material was precipitated in methanol and purified by repetitive Soxhlet extractions with acetone, $n$-hexane and chloroform. The chloroform fraction was again precipitated in methanol and filtered, yielding a blue solid (102 mg, 80\%). SEC (THF, $40{ }^{\circ} \mathrm{C}, \mathrm{PS}$ standards): $M_{\mathrm{n}}=9 \mathrm{~kg} \mathrm{~mol}^{-1}, \oplus=1.4$. UV-Vis (film): $\lambda_{\max }=677 \mathrm{~nm}$.

PCPDTTPD P2. Synthesis according to the general polymerization procedure: (4-(2ethylhexyl)-4-(2-(2-(2-methoxyethoxy)ethoxy)ethyl)-4H-cyclopenta[2,1-b:3,4- $\left.b^{\prime}\right]$ dithiophene2,6-diyl)bis(trimethylstannane) (6) (75.7 mg, 0.099 mmol), TPD 17 (42.0 mg, 0.099 mmol), dry toluene $(2.0 \mathrm{~mL})$, dry DMF $(0.4 \mathrm{~mL})$. The polymer was obtained as a blue solid $(43 \mathrm{mg}, 62 \%)$. SEC (THF, $40{ }^{\circ} \mathrm{C}$, PS standards): $M_{\mathrm{n}}=10 \mathrm{~kg} \mathrm{~mol}^{-1}, \oplus=1.3$. UV-Vis (film): $\lambda_{\max }=627 \mathrm{~nm}$.

PCPDTTPD P3. Synthesis according to the general polymerization procedure: (4,4-bis(2-(2methoxyethoxy)ethyl)-4H-cyclopenta[2,1-b:3,4-b']dithiophene-2,6-diyl)bis(trimethylstannane) (9) (139 mg, $0.196 \mathrm{mmol}$ ), TPD 17 ( $83 \mathrm{mg}, 0.196 \mathrm{mmol}$ ), dry toluene ( $2.5 \mathrm{~mL}$ ), dry DMF $(0.5 \mathrm{~mL})$. The polymer was obtained as a blue solid $(76 \mathrm{mg}, 60 \%)$. SEC (THF, $40{ }^{\circ} \mathrm{C}, \mathrm{PS}$ standards): $M_{\mathrm{n}}=17 \mathrm{~kg} \mathrm{~mol}^{-1}, \bigoplus=1.6$. UV-Vis (film): $\lambda_{\max }=641 \mathrm{~nm}$. 
PCPDTTPD P4. Synthesis according to the general polymerization procedure: (4,4-bis(2-(2methoxyethoxy)ethyl)-4H-cyclopenta[2,1-b:3,4-b']dithiophene-2,6-diyl)bis(trimethylstannane) (9) (50.5 mg, $0.0713 \mathrm{mmol}), 1,3$-dibromo-5-(2-(2-methoxyethoxy)ethyl)-4H-thieno[3,4c]pyrrole-4,6(5H)-dione (15) (29.5 $\mathrm{mg}, 0.0713 \mathrm{mmol})$, dry toluene $(2 \mathrm{~mL})$, dry DMF $(0.4 \mathrm{~mL})$. The polymer was obtained as a blue solid (36 mg, 79\%). SEC (THF, $40{ }^{\circ} \mathrm{C}$, PS standards): $M_{\mathrm{n}}=$ $22 \mathrm{~kg} \mathrm{~mol}^{-1}, \ominus=1.6$. UV-Vis (film): $\lambda_{\max }=649 \mathrm{~nm}$.

\section{Dielectric constant measurements}

Impedance spectroscopy was performed in the range of $100 \mathrm{~Hz}$ to $1 \mathrm{MHz}$ using a Solatron 1260 impedance gain-phase analyzer with an AC drive voltage of $10 \mathrm{mV}$. All measurements were performed in $\mathrm{N}_{2}$ at room temperature. Commercially available glass substrates patterned with ITO in four different dimensions $\left(0.095,0.1616,0.357\right.$ and $0.995 \mathrm{~cm}^{2}$ ) were used as bottom electrode of the capacitors. The substrates were cleaned with soap/water solution, de-ionized water flushing, and sonication with acetone and isopropyl alcohol, followed by oven drying and UV-O ${ }_{3}$ treatment. PEDOT:PSS (VP Al4083, H.C. Starck) was spincast in ambient conditions and oven dried at $140{ }^{\circ} \mathrm{C}$ for $10 \mathrm{~min}$. All films were spun from chloroform under $\mathrm{N}_{2}$ atmosphere and the Al top electrodes were deposited at a pressure of ca. $10^{-6} \mathrm{mbar}$ by thermal evaporation.

\section{Solar cell and OFET fabrication and characterization}

Before device processing, the indium tin oxide (ITO, Kintec, $100 \mathrm{~nm}, 20 \mathrm{Ohm} \mathrm{sq}^{-1}$ ) containing substrates were thoroughly cleaned through sonication using soap, demineralized water, acetone, isopropyl alcohol and a UV-O ${ }_{3}$ treatment. Subsequently, a layer of PEDOT:PSS (Heraeus Clevios Al 4083) was spin-coated on top of the pre-patterned ITO substrates. Further processing was performed under $\mathrm{N}_{2}$ atmosphere in a glove box, starting with an annealing step at $130{ }^{\circ} \mathrm{C}$ for $15 \mathrm{~min}$ to remove any residual water. The polymer:[70]PCBM (> 99\%, Solenne) active layers were spin-coated targeting thicknesses between 80 and $120 \mathrm{~nm}$, as confirmed by profilometry (DEKTAK). The blend solutions providing highest efficiencies (P3) contained a 1:1.5 (polymer:[70]PCBM) ratio, with polymer concentrations of $10 \mathrm{mg} \mathrm{mL}^{-1}$, using $o$-dichlorobenzene as the processing solvent (see Table 2). On top of the active layer, Ca was evaporated in vacuo with a thickness of $30 \mathrm{~nm}$, and the devices were finished off with $\mathrm{Al}$ as the top electrode, with a thickness of $80 \mathrm{~nm}$. The active area $\left(3.08 \mathrm{~mm}^{2}\right)$ was defined using a mask. The output parameters of the BHJ polymer solar cells were measured using a Newport class A solar simulator (model 91195A), calibrated with a silicon solar cell to give a 1 sun AM $1.5 \mathrm{G}$ spectrum. EQE measurements were performed with a Newport Apex illuminator (100 W xenon lamp, 6257) as light source, a Newport Cornerstone 130 monochromator and a Stanford SR830 lock-in amplifier for the current measurements. Calibration was done with a certificated Si FDS-100 photodiode. For AFM imaging, a Park NX10 (manufactured by Park Systems) was used to image topography in non-contact mode. In non-contact mode, the AFM cantilever is vibrated near the surface of the sample. The distance between the cantilever and the sample during operation can be in the order of angstroms. This distance is dictated by the van der Waals forces that repel the cantilever at very close distances. Acta probes were used, manufactured by AppNano, which have a nominal spring constant of $37 \mathrm{~N} \mathrm{~m}^{-1}$ and a nominal cantilever length of $125 \mu \mathrm{m}$. 
Field-effect transistors were prepared by spin-coating the polymers from chloroform with a concentration of $5 \mathrm{mg} \mathrm{mL}^{-1}$ on $200 \mathrm{~nm}$ of thermally grown $\mathrm{SiO}_{2}$. The gate contact consisted of highly $\mathrm{n}$-doped Si. Interdigitated source and drain electrodes were pre-patterned, comprising of a stack of Ti/Au (10/100 nm). FET substrates were acquired from Philips. The channel length was $10 \mu \mathrm{m}$. Two Keithley 2400 source meters were used to measure the $I_{D s}$ and correct it for leakage through the gate electrode. All FET preparations and characterizations were carried out in a $\mathrm{N}_{2}$ filled glovebox. 


\section{References}

[1] S. Sax, N. Rugen-Penkalla, A. Neuhold, S. Schuh, E. Zojer, E. J. W. List and K. Müllen, Adv. Mater., 2010, 22, 2087.

[2] C. Kanimozhi, N. Yaacobi-Gross, K. W. Chou, A. Amassian, T. D. Anthopoulos and S. Patil, J. Am. Chem. Soc., 2012, 134, 16532.

[3] R. D. Jansen-van Vuuren, A. Armin, A. K. Pandey, P. L. Burn and P. Meredith, Adv. Mater., 2016, 28, 4766.

[4] A. Polman, M. Knight, E. C. Garnett, B. Ehrler and W. C. Sinke, Science, 2016, 352, aad4424.

[5] B. Russ, A. Glaudell, J. J. Urban, M. L. Chabinyc and R. A. Segalman, Nat. Rev. Mater., 2016, 1, 16050.

[6] G. Dennler, M. C. Scharber and C. J. Brabec, Adv. Mater., 2009, 21, 1323.

[7] M. Kaltenbrunner, M. S. White, E. D. Głowacki, T. Sekitani, T. Someya, N. S. Sariciftci and S. Bauer, Nat. Commun., 2012, 3, 770.

[8] Y. W. Su, S. C. Lan and K. H. Wei, Mater. Today, 2012, 15, 554.

[9] S. B. Darling and F. You, RSC Adv., 2013, 3, 17633.

[10] S. Lizin, S. Van Passel, E. De Schepper, W. Maes, L. Lutsen, J. Manca and D. Vanderzande, Energy Environ. Sci., 2013, 6, 3136.

[11] L. Dou, J. You, Z. Hong, Z. Xu, G. Li, R. A. Street and Y. Yang, Adv. Mater., 2013, 25, 6642.

[12] K. A. Mazzio and C. K. Luscombe, Chem. Soc. Rev., 2015, 44, 78.

[13] H. Kang, G. Kim, J. Kim, S. Kwon, H. Kim and K. Lee, Adv. Mater., 2016, 28, 7821.

[14] K. Müllen and W. Pisula, J. Am. Chem. Soc., 2015, 137, 9503.

[15] W. C. Zhao, S. Li, H. Yao, S. Zhang, Y. Zhang, B. Yang and J. Hou, J. Am. Chem. Soc., 2017, 139, 7148.

[16] S. H. Park, A. Roy, S. Beaupré, S. Cho, N. Coates, J. S. Moon, D. Moses, M. Leclerc, K. Lee and A. J. Heeger, Nat. Photonics, 2009, 3, 297.

[17] M. Knupfer, Appl. Phys. A, 2003, 77, 623.

[18] M. Breselge, I. Van Severen, L. Lutsen, P. Adriaensens, J. Manca, D. Vanderzande and T. Cleij, Thin Solid Films, 2006, 511-512, 328.

[19] F. Jahani, S. Torabi, R. C. Chiechi, L. J. A. Koster and J. C. Hummelen, Chem. Commun., 2014, 50, 10645.

[20] J. E. Donaghey, A. Armin, P. L. Burn and P. Meredith, Chem. Commun., 2015, 51, 14115.

[21] L. J. A. Koster, S. E. Shaheen and J. C. Hummelen, Adv. Energy Mater., 2012, 2, 1246.

[22] G. Zhang, T. M. Clarke and A. J. Mozer, J. Phys. Chem. C, 2016, 120, 7033.

[23] M. Lenes, L. J. A. Koster, V. D. Mihailetchi and P. W. M. Blom, Appl. Phys. Lett., 2006, 88, 243502.

[24] X. Chen, Z. Zhang, Z. Ding, J. Liu and L. Wang, Angew. Chem. Int. Ed., 2016, 55, 10376.

[25] Q. Deng, Y. Li, L. Chen, S. Wang, G. Wang, Y. Sheng and G. Shao, Mod. Phys. Lett. B, 2016, 30, 1650341.

[26] K. Lu, J. Fang, X. W. Zhu, H. Yan, D. H. Li, C. A. Di, Y. L. Yang and Z. X. A. Wei, New J. Chem., 2013, 37, 1728.

[27] D. A. Gedefaw, Y. Zhou, Z. Ma, Z. Genene, S. Hellström, F. Zhang, W. Mammo, O. Inganäs and M. R. Andersson, Polym. Int., 2014, 63, 22.

[28] S. Torabi, F. Jahani, I. Van Severen, C. Kanimozhi, S. Patil, R. W. A. Havenith, R. C. Chiechi, L. Lutsen, D. J. M. Vanderzande, T. J. Cleij, J. C. Hummelen and L. J. A. Koster, Adv. Funct. Mater., 2015, 25, 150. 
[29] B. Meng, H. Y. Song, X. X. Chen, Z. Y. Xie, J. Liu and L. X. Wang, Macromolecules, 2015, 48, 4357.

[30] Y. Chen, S. Zhang, Y. Wu and J. Hou, Adv. Mater., 2014, 26, 2744.

[31] T. R. Andersen, T. T. Larsen-Olsen, B. Andreasen, A. P. L. Böttiger, J. E. Carlé, M. Helgesen E. Bundgaard, K. Norrman, J. W. Andreasen, J. W. Jorgensen and F. C. Krebs, ACS Nano, 2011, 5, 4188.

[32] M. Lenes, F. B. Kooistra, J. C. Hummelen, I. Van Severen, L. Lutsen, D. Vanderzande, T. J. Cleij and P. W. M. Blom, J. Appl. Phys., 2008, 104, 114517.

[33] J. Brebels, L. Lutsen, J. Manca, D. Vanderzande and W. Maes, J. Mater. Chem. A, 2017, DOI: 10.1039/C7TA06808E.

[34] C. M. MacNeill, E. D. Peterson, R. E. Noftle, D. L. Carroll and R. C. Coffin, Synth. Met., 2011, 161, 1137.

[35] Z. Li, S.-W. Tsang, X. Du, L. Scoles, G. Robertson, Y. Zhang, F. Toll, Y. Tao, J. Lu and J. Ding, Adv. Funct. Mater., 2011, 21, 3331.

[36] M. Guo, T. Hayakawa, M.-A. Kakimoto and T. Goodson, J. Phys. Chem. B, 2011, 115, 13419.

[37] Y. Lu, Z. Xiao, Y. Yuan, H. Wu, Z. An, Y. Hou, C. Gao and J. Huang, J. Mater. Chem. C, 2013, 1,630 .

[38] P. Yang, M. Yuan, D. F. Zeigler, S. E. Watkins, J. A. Lee and C. K. Luscombe, J. Mater. Chem. C, 2014, 2, 3278.

[39] N. Cho, C. W. Schlenker, K. M. Knesting, P. Koelsch, H.-L. Yip, D. S. Ginger and A. K.-Y. Jen, Adv. Energy Mater., 2014, 4, 1301857.

[40] S. Van Mierloo, P. Adriaensens, W. Maes, L. Lutsen, T. Cleij, E. Botek, B. Champagne and D. Vanderzande, J. Org. Chem., 2010, 75, 7202.

[41] W. Vanormelingen, P. Verstappen, V. Maes, D. Bevk, L. Lutsen, D. Vanderzande and W. Maes, Synlett, 2013, 24, 2389.

[42] K. Kawabata, M. Takeguchi and H. Goto, Macromolecules, 2013, 46, 2078.

[43] J. Shi, W. Zhao, L. Xu, Y. Kan, C. Li, J. Song and H. Wang, J. Phys. Chem. C, 2014, 118, 7844. [44] G. Griffini, J. D. Douglas, C. Piliego, T. W. Holcombe, S. Turri, J. M. J. Fréchet and J. L. Mynar, Adv. Mater., 2011, 23, 1660.

[45] T. Vangerven, P. Verstappen, J. Drijkoningen, W. Dierckx, S. Himmelberger, A. Salleo, D. Vanderzande, W. Maes and J. V. Manca, Chem. Mater., 2015, 27, 3726.

[46] P. Verstappen, I. Cardinaletti, T. Vangerven, W. Vanormelingen, F. Verstraeten, L. Lutsen, D. Vanderzande, J. Manca and W. Maes, RSC Adv., 2016, 6, 32298.

[47] G. Pirotte, P. Verstappen, D. Vanderzande and W. Maes, Adv. Electron. Mater., manuscript accepted.

[48] F. Brouwer, J. Alma, H. Valkenier, T. P. Voortman, J. Hillebrand, R. C. Chiechi and J. C. Hummelen, J. Mater. Chem., 2011, 21, 1582.

[49] R. L. Danley, P. A. Caulfield and S. R. Aubuchon, Am. Lab., 2008, 40, 9.

[50] S. Trasatti, Pure Appl. Chem., 1986, 58, 955.

[51] J. Bard and L. R. Faulkner, Electrochemical Methods: Fundamentals and Applications, 2nd Ed., 2001, Wiley.

[52] C. Piliego, T. W. Holcombe, J. D. Douglas, C. H. Woo, P. M. Beaujuge and J. M. J. Fréchet, J. Am. Chem. Soc., 2010, 132, 7595. 